Vol. 9 (1): 75-82 (2019)

\title{
GEOBOTANIC CHARACTERISTICS OF VEGETATION IN THE BAIKAL STATE BIOSPHERE RESERVE
}

\author{
Elena Martusova ${ }^{1}$, Alexander Sizykh ${ }^{2 *}$, Alexey Shekhovtsov ${ }^{3}$ \\ ${ }^{1}$ Baikal State Biosphere Reserve, 671220, st. Tankhoi 34, Buryat Republic, Russia; \\ ${ }^{2 *}$ Siberian Institute of Plant Physiology, SB RAS, 664033, Irkutsk, Lermontova str., 132, Russia; \\ ${ }^{3}$ V.B. Sochava Institute of Geography SB RAS, 664033, Irkutsk, Ulan-Batorskaya str., 1, Russia; \\ "Corresponding author: Alexander Sizykh, e-mail: alexander.sizykh@gmail.com;
}

Received November, 2018; Accepted December, 2018; Published January, 2019;

DOI: https://doi.org/10.31407/ijees9110 UOI license: http://u-o-i.org/1.01/ijees/06785744

\begin{abstract}
The vegetation was studied along a definite itinerary and was aimed to reveal a detailed structure of the communities at the natural reserve territory. The results the geobotanic descriptions of the vegetation of the Pereyomnaya and Abiduy Rivers basins as key sites for research of the reserve vegetation for all of the reserve were showed. And we added additional information on the structure of the plant communities obtained for last time investigation of the reserve vegetation. The territory of Baikal Biosphere Reserve organized in 1969 represents a unique area of the vegetation structure in Southern Pre-Baikal region.
\end{abstract}

Key words: geobotanic characteristics of vegetation, southern Pre'Baikal, Baikal state biosphere reserve 